\title{
Follow-up survey of the pediatric gastroenterology fellowship class of 2007: Where are they now?
}

\author{
Cary Qualia ${ }^{1 *}$, Myriah Z Tarantelli ${ }^{2}$, Michelle Hughes ${ }^{3}$ and Constance D Baldwin ${ }^{4}$ \\ ${ }^{1}$ Division of Pediatric Gastroenterology, Department of Pediatrics, Albany Medical Center, USA \\ ${ }^{2}$ Department of Pediatrics, Vanderbilt University Medical Center, USA \\ ${ }^{3}$ Department of Internal Medicine, Boston University School of Medicine, USA \\ ${ }^{4}$ Department of Pediatrics, University of Rochester Medical Center, USA
}

\begin{abstract}
Objectives: Pediatric gastroenterologists are expected to acquire skills as clinicians, researchers, and educators during their fellowship training. An e-mail survey was conducted in 2010 to determine how well training experiences prepared graduates for their roles as attending physicians.

Methods: A follow-up survey was e-mailed to the 50 pediatric gastroenterologists who had responded to a previous survey conducted in 2006 (JPGN 47:327-22, 2008).

Results: Surveys were completed by 35 physicians. Of these, 24 (68.5\%) spend at least $75 \%$ of their time in the clinical arena. Only 9 of 35 respondents (26\%) spend $>25 \%$ of their time conducting clinical and/or basic science research. Eighteen respondents (51\%) are not currently involved in any type of research activity. Using Fisher's Exact Test, there was no association between the amount of time spent conducting research as a fellow and the amount of time devoted to research as an attending physician $(p=0.28)$.

Conclusion: Despite pediatric gastroenterology fellowship programs requiring trainees to devote a substantial amount of time to research activities, only a relatively small percentage of graduates pursue careers as researchers. The survey did not ask whether this resulted from personal preference, funding limitations, or job restrictions. The current pediatric gastroenterology training guidelines recommend allowing fellows to structure their training experiences in ways that will prove most beneficial to their future careers. A question for further study is whether the mismatch in time allocation for research suggests over-emphasis on research in fellowship, or under-emphasis on research in academic practice.
\end{abstract}

\section{Introduction}

Pediatric gastroenterology fellows are expected to acquire skills as clinicians, researchers, and educators during their training, but it is difficult to standardize formal training in clinical, research, and teaching skills. The Accreditation Council for Graduate Medical Education specifies that residents and fellows must acquire six core competencies, including medical knowledge, interpersonal and communication skills, patient care, systems-based practice, practice-based learning and improvement, and professionalism [1]. To learn these competencies, each physician is likely to need different amounts of time in clinical activities, including the acquisition of procedural skills. Standardized requirements for learning skills in research and education have been slower to evolve.

Recently, the North American Society of Pediatric Gastroenterology, Hepatology, and Nutrition [2] updated its guidelines published in 1999 for training in Pediatric Gastroenterology. While both sets of guidelines discuss the clinical aspects of training in detail, the updated guidelines highlight the fact that fellowship training must provide individuals with the skills that will enable them to pursue careers as researchers and medical educators, if they chose to do so [2,3]. Prior to 2004, pediatric gastroenterology fellows were required to publish a paper in a peer-reviewed journal to qualify to take their subspecialty boards. During that year, changes to fellowship training requirements made by the American Board of Pediatrics enabled fellows to satisfy their research requirement by producing a "work product" as evidence of participation in scholarly activity. Examples of such a work product are a peer-reviewed publication, a formal report describing a completed or complex ongoing activity, a peer-reviewed extramural grant application, or a thesis [4].

Ideas may change over time regarding the ideal amount of time trainees should spend on specific kinds of training during fellowship. In a survey of 76 current and past pediatric infectious disease fellows, $78 \%$ of graduates thought 3 years to be an ideal duration of fellowship training, compared with only $54 \%$ of fellows [5]. In a much larger study, more than half of current pediatric infectious disease fellows $(\mathrm{n}=390)$ would have chosen a 2 -year fellowship without research or scholarly activity over the current 3-year structure [6]. However, research training via a Master of Public Health degree, sometimes completed within the timeframe of a fellowship program, continues to attract physicians interested in a career of clinical investigation. A retrospective review of the career choices of 25 fellows who entered the

${ }^{*}$ Correspondence to: Cary Qualia, Division of Pediatric Gastroenterology, Department of Pediatrics, Albany Medical Center, 43 New Scotland Avenue, MC-88, Albany, NY, USA, Tel: 518-262-8831; E-mail: qualiac@mail.amc.edu

Key words: fellowship training, pediatric gastroenterology

Received: June 11, 2018; Accepted: June 25, 2018; Published: June 29, 2018 
Academic Clinical Research Track at Brigham and Women's Hospital showed that of the 13 who received a Master of Public Health (MPH) degree, 10 (77\%) obtained external funding for clinical research within 3 years of completing their fellowship. The authors concluded that formal clinical research training culminating in an MPH degree was extremely valuable in the initiation of a successful career as a clinical investigator [7]. The opinions of respondents of the current survey regarding the ideal duration of pediatric gastroenterology training was not solicited.

The present study was conducted to assess how well fellowship training experiences prepared pediatric gastroenterologists for their roles as attending physicians after 3 years in practice. This study is a follow up of a 2007 survey sent to pediatric gastroenterologists who were completing their fellowship training at that time. Both surveys asked physicians to report on their current professional activities and self-assess their preparation for clinical, educational, and research roles after fellowship. The present survey allowed assessment of changes in their activities and perspectives on fellowship training after 3 years.

\section{Materials and methods}

We developed and distributed a 70 question follow up survey, which was emailed in December 2010 to the 50 pediatric gastroenterologists who responded to the initial survey conducted in 2006 [8]. Email addresses were obtained from the NASPGHAN membership directory. Survey questions were based on those included in the 2006 survey, and covered the general areas of patient care, research activities, involvement in formal teaching, and self-assessment of research and teaching skills. Self-assessment of skills was accomplished using the same scoring system chosen for the initial survey (scale of 1 to 5 , where $1=$ Novice, 2 = Advanced Beginner, 3 = Competent, $4=$ Proficient, and 5 = Expert). This study was approved by the Institutional Review Board at Albany Medical Center in Albany, NY.

\section{Results}

\section{Sample}

Surveys were completed by 35 physicians ( $70 \%$ response rate). Of these, $24(68.5 \%)$ spend at least $75 \%$ of their time in the clinical area. Twenty six percent of respondents spent at least $70 \%$ of their time seeing outpatients in an office setting and $51 \%$ devote at least $50 \%$ of their work week to this activity. The average respondent spent 30 minutes with new patients and 20 minutes with established patients.

\section{Clinical skills}

Most respondents (94\%) thought they received adequate procedural training during fellowship and $91 \%$ thought they had been appropriately trained to provide high quality care for patients. Respondents performed an average of 4.6 esophagogastroduodenoscopies (EGDs) and 2.5 colonoscopies per week. Using Fisher's Exact Test, which defines a statistically significant correlation as a $p$ values of $<0.05$, it was determined that there was no statistical association between the number of EGDs performed during fellowship and the number performed as an attending physician $(p=0.99)$. However, for colonoscopies, physicians who performed $>150$ colonoscopies during their training performed more colonoscopies per week as attending physicians than those who performed $<150$ of these procedures during fellowship $(p=0.043)$ (Table 1). While 13 of 35 respondents (37\%) are currently performing liver biopsies, only 4 of 35 (11\%) perform paracenteses.
Table 1. Number of EGDs and colonoscopies performed during fellowship compared to number performed as an attending

\begin{tabular}{|l|l|l|l|}
\hline EGDs & & & \\
\hline & $0-5$ & $\geq 6$ & \\
\hline$<150$ & 11 & 6 & \\
\hline$>150$ & 12 & 5 & $P=0.99$ \\
\hline Colonoscopies & & & \\
\hline & $0-3$ & $\geq 4$ & \\
\hline $0-100$ & 12 & 3 & \\
\hline $101-149$ & 13 & 0 & \\
\hline$\geq 150$ & 4 & 3 & $P=0.043$ \\
\hline
\end{tabular}

\section{Research skills}

Another portion of the survey addressed research activity. Eighteen respondents (51\%) were not currently involved in any type of research activity. Only 9 of 35 respondents (26\%) spent $>25 \%$ of their time conducting clinical and/or basic science research, and all of these were responsible for securing part or all their funding. Among those doing research, $57 \%$ had research assistants (fellows, house officers, or others). Of the 25 respondents who spent over half of their time in fellowship conducting research, only $9(36 \%)$ currently spent at least $25 \%$ of their time conducting research now. Using Fisher's Exact Test, there was no association between the amount of time spent conducting research as a fellow and the amount of time devoted to research activity as an attending physician $(p=0.28)$. Not surprisingly, attending physicians who spent at least half of their time engaged in some type of research activity had more publications on average than those spending less than half of their time on research (12.1 publications vs. 3.2, respectively). These publications included original articles, abstracts, review articles, and book chapters.

When asked to self-assess their research skills during fellowship, respondents gave themselves a mean score of 15.8 out of a maximum composite score of 30 , while their average self-rating as attending physicians was nearly identical (15.4) (Figure 1). Moreover, using Fisher's Exact Test, we found that devoting more time to research as a fellow was not associated with higher self-assessed research skills as attending physicians $(P=1.0)$ (Table 2$)$.

Those physicians with graduate degrees other than a MD or DO had an average self-assessment score for research skills of 19.6 out of a total possible composite score of 30 , while those without these degrees had an average grade of 13.4. We noted that all 11 physicians holding graduate degrees other than a MD or DO spent some time as attending physicians conducting research, but only 4 of these 11 devote $>50 \%$ of their time to conducting clinical and/or basic science research.

\section{Educational skills}

Another set of survey question dealt with education. Attending physicians who worked in teaching hospitals gave an average of 10.6 formal lectures yearly, including grand rounds presentations. The average self-assessment score for teaching skills during fellowship was 18.4 out of a maximum composite score of 25 , while the average score for teaching skills as attending physicians was only slightly higher (18.8) (Figure 2). While $48 \%$ of respondents received formal training in medical education as trainees, only $40 \%$ received this as attending physicians. Of the 24 attending physicians that received feedback on the formal lectures they give, 17 (71\%) believed that this improved their presentation skills.

Respondents were asked whether they would recommend any changes be made to the amount of time they devoted to patient care, 
Table 2. Attending self-assessment score as compared to time devoted to research activities during fellowship training

\begin{tabular}{|c|c|c|c|}
\hline & $<\mathbf{5 0} \%$ & $>\mathbf{5 0} \%$ & \\
\hline $0-15$ & 6 & 13 & \\
\hline $16-30$ & 4 & 11 & $P=1.0$ \\
\hline
\end{tabular}

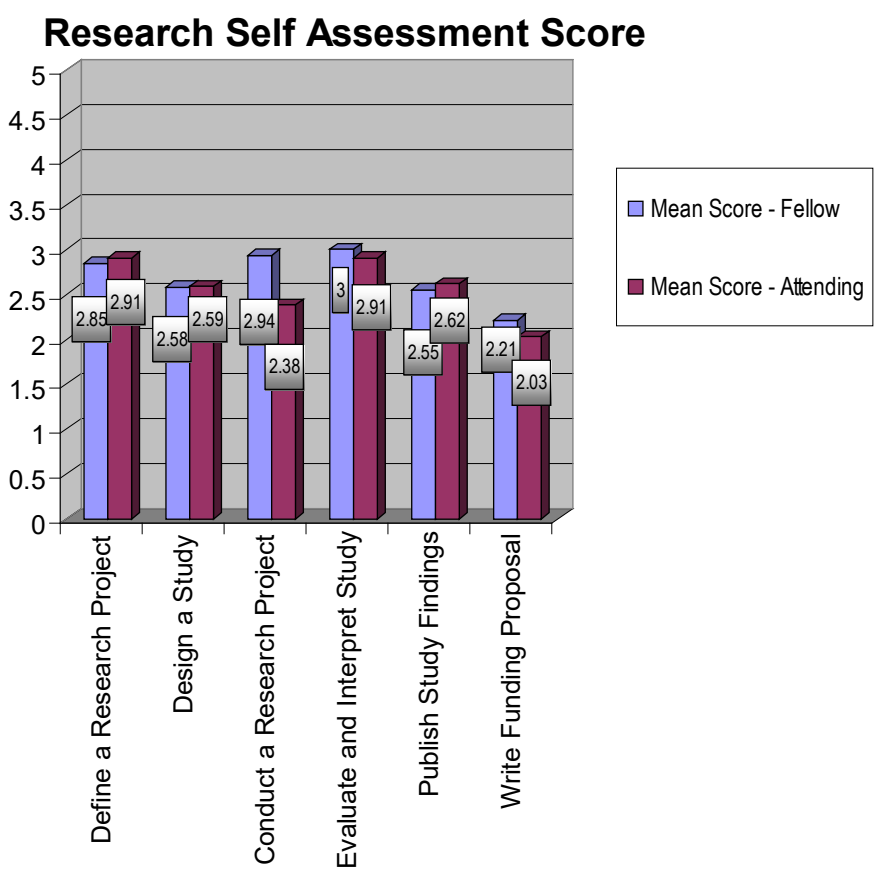

Figure 1. Research Self-Assessment Score. Mean score of fellows compared to those of attending physicians for each research skill assessed

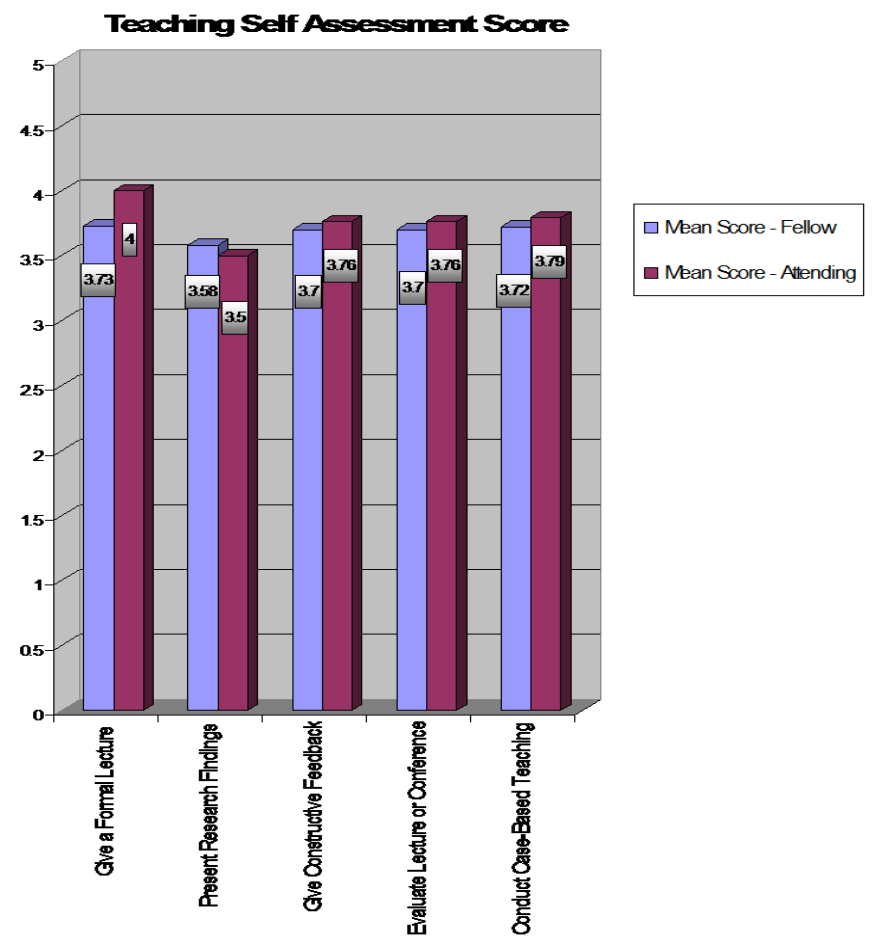

Figure 2. Teaching Self-Assessment Score. Mean score of fellows compared to those of attending physicians for each teaching skill assessed research, and teaching activities during their fellowship training (more than one change could be recommended). Seventeen of 35 (49\%) did not recommend any changes. Twelve of 35 (34\%) would have liked to have spent more time caring for patients during their fellowships, and 9 of 35 (26\%) wanted to have devoted more time to teaching activities (either teaching themselves or learning how to teach effectively). Only one respondent would have devoted more time to conducting research or research training as a fellow.

\section{Job satisfaction}

We found that of the 30 respondents who thought they had accepted their ideal job at the time they chose it during their fellowship, only 6 thought their current roles as attendings matched their ideal job description regarding the types of work they do, and the amount of time devoted to these activities (clinical, research, and teaching). Eight of 30 were doing overall the type of work they wanted to do, but thought they were devoting more time than they would like to certain work responsibilities. Sixteen respondents (53\%) felt their current roles did not allow them to perform the types of work they wanted to or to devote the amount of time they wanted to each specific job duty.

\section{Discussion}

Results of the 2013 survey show that many pediatric gastroenterology attendings who graduated from fellowship in 2007 would have welcomed the opportunity to devote more time to patient care during their training. This finding is not surprising, since most of these pediatric gastroenterologists spent at least three quarters of their time caring for patients as attending physicians and believed they would have benefited from more patient encounters as fellows. More than half of respondents were not currently engaged in any type of research activity. For those who were, devoting more time to research activities as a trainee did not seem to result in increased confidence in their research skills. The results of this survey suggest that pediatric gastroenterology fellows, in retrospect, would appreciate having had the flexibility to structure their training experiences to match their interests and future work.

This finding supports the current NASPGHAN training guidelines, which aim to allow trainees to structure their individual training experience in ways that will be of greatest benefit to their careers. For example, if fellows seek to obtain expertise in a specific area, such as the management of children with intestinal failure, the guidelines state that up to 9 months can be devoted to this special interest. The guidelines also state that fellows should be given the opportunity to pursue advanced degrees if they are interested in pursuing academic careers, and that local institutional resources should be used for this purpose [3]. This move towards individualizing training experiences appears to be a step in the right direction, especially given the ever-growing wealth of medical knowledge and the increasing amount of time and effort that needs to be devoted to securing funding for research and conduct it well. In other words, it can be challenging for any one physician to be highly productive both as a clinician and as a researcher. To afford each individual subspecialist, the best chance of productivity and career success, training needs to be geared towards the fellow's specific interests and goals.

In the small cohort of early career pediatric gastroenterologists discussed in this paper, $51 \%$ of graduates reported spending at least half of their work week caring for outpatients in an office setting. Given 
the relatively short time that physicians must spend with individual outpatients, they need to be very proficient at eliciting histories, performing physical examinations, deriving differential diagnoses, and constructing diagnostic and treatment algorithms. We believe that these skills can best be acquired through enough patient encounters during fellowship training. The updated NASPGHAN guidelines recommend that trainees devote at least 15 months to clinical training in inpatient and ambulatory settings and suggest that a significant component of training in the ambulatory setting should be considered, since clinical pediatric gastroenterology is predominantly an outpatient practice [3]. Our data suggest that these recommendations are appropriate.

Of the pediatric gastroenterologists who responded to our survey, $94 \%$ believed that their training sufficiently prepared them to perform the procedures required in practice. Such self-ratings may not be accurate, however. Procedural skills of most of these physicians have not been formally or objectively assessed, and the literature suggests that fellowship training may not adequately prepare attendings to master these procedures. According to the updated NASPGHAN guidelines, the recommended number of colonoscopies a graduating pediatric fellow should perform during their training is 120 [3], and our previous study showed that many graduating fellows performed fewer [9]. The literature suggests that 200 to 300 of these procedures may be needed to attain competence $[10,11]$. Our previous study showed that most graduating fellows also performed fewer liver biopsies and paracenteses than recommended by the NASPGHAN guidelines [9]. Regarding procedural training, the new NASPGHAN guidelines take into consideration that it is impossible for all trainees to perform the recommended number of all procedures, and that performing a certain number of a specific procedure does not necessarily demonstrate competency. They recommend that for some procedures, learners should aim to "understand the principles" rather than "demonstrate competence" in performing them $[3,8]$.

In our survey, $74 \%$ of respondents devoted $<25 \%$ of their time to research related endeavors. Additionally, only 4 of 11 respondents with degrees other than a MD or DO spend $>50 \%$ of their time conducting basic science and/or clinical research. Given that approximately $50 \%$ of fellowship time is devoted to research, on average, the research efforts of graduates after training seem low. Although we did not ask why respondents did or did not pursue careers as researchers, a combination of factors may explain this result, including personal preferences, employer demands, and escalating funding challenges. The opportunity for physicians to conduct research depends heavily on external and/or intramural funding and obtaining grants can be limited by time constraints related to the burden of patient care responsibilities, the skill set of the researcher, and the availability of research dollars. It is possible that some fellowship graduates would like to be doing more research than their job demands allow. The ideal proportion of academic pediatric gastroenterologists who should be doing research to advance the field and improve patient outcomes is not known.

In the current survey, the average self-assessed teaching score among survey respondents increased only slightly over a 3 -year period. This may be attributable to fellows not having enough opportunities to teach during their training or later the job. No formal guidelines recommend the appropriate scope of educational training for gastroenterology fellows. Yet these skills are important, as many graduating fellows go on to work in academic centers where they teach both formally and informally. Some training programs formally educate future faculty to become teachers. For example, the Fellows as Clinician-Educators (FACE) program is a 1-year program open to fellows and chief residents in the department of internal medicine at the University of Iowa. Trainees complete a three-station Objective Structured Teaching Examination using standardized learners, who assess participants' skills in giving feedback, outpatient precepting, and giving a mini-lecture. For 2 of the 3 cases, fellows demonstrate statistically significant improvement on overall scores after participating in the program and their self-assessments of teaching skills improve [12]. This and other programs [13], could provide useful models for improvement of fellowship curricula. Perhaps if departments implemented formal teach-the-teacher programs for fellows and for faculty, gastroenterologists would be more confident in their teaching abilities. The need for such programs might be evaluated based on the quality and outcomes of fellowship graduates as well as the amount of teaching that faculty consider optimal for job satisfaction.

\section{Limitations}

The small sample size of this study precludes evaluation of significant associations between fellows' training experiences and their self-perceived abilities as clinicians, researchers, and teachers after they become attending physicians. Data depend exclusively on self-report, and therefore may be prone to social desirability bias, inaccurate self-assessment, or memory error. In addition, we focused exclusively on fellows who graduated in 2007, and their experiences may differ from those of their more senior colleagues, or from their own future experiences later in their careers. Finally, it is important to note that all physicians continue to learn and further develop their skills post-fellowship, regardless of how much time they devoted to the clinical, research, and teaching arenas during their fellowship years. Formal "training time" does not equal "practice time." This is especially true in the conduct of clinical and basic science research: planning, implementing, and writing up results of projects is a continuing educational process.

Future studies should draw on a larger sample of practicing pediatric gastroenterologists at different stages in their professional development. In addition, in a larger, well-funded study, the skills of the respondents in clinical procedures, research and teaching should be measured objectively to provide more valid data on "real world" performance. Self-reporting of skills, however, is a reasonable measure of a respondents' confidence in their performance and provides useful information that pertains to perceived training quality and job satisfaction.

\section{Conclusion}

Most pediatric gastroenterologists spend most of their time in the outpatient clinical arena. Even though pediatric gastroenterology fellowship programs require trainees to devote a substantial amount of time to research activities, only a relatively small percentage of graduates pursue careers as researchers. The recently revised pediatric gastroenterology training guidelines emphasize allowing fellows to structure their training experiences in ways that will prove most beneficial to their future careers [3]. We found that only $20 \%$ of pediatric gastroenterologists believe their current roles match their ideal job description. Affording trainees, the time and resources to become more proficient in the specific skills needed for activities that most interest them, whether they be in patient care, teaching, or research, may help them to become more proficient and independent in their work, so they can structure their roles as attending physicians in ways that offer more job satisfaction. 


\section{References}

1. Liacouras CA, Furuta GT, Hirano I, Atkins D, Attwood SE, et al. (2011) Eosinophilic Esophagitis: Updated consensus recommendations for children and adults. $J$ Allergy Clin Immunol 128: 3-20. [Crossref]

2. Soon IS, Butzner JD, Kaplan GG, deBruyn JC (2013) Incidence and prevalence of eosinophilic esophagitis in children. J Pediatr Gastroenterol Nutr 57: 72-80. [Crossref]

3. Sealock RJ, Rendon G, El-Serag HB (2010) Systematic review: the epidemiology of eosinophilic oesophagitis in adults. Aliment Pharmacol Ther 32: 712-719. [Crossref]

4. Ronkainen J, Talley NJ, Aro P, Storskrubb T, Johansson SE, et al. (2007) Prevalence of oesophageal eosinophils and eosinophilic oesophagitis in adults: the population-based Kalixanda study. Gut 56: 615-620. [Crossref]

5. Straumann A, Simon HU (2005) Eosinophilic esophagitis: escalating epidemiology? J Allergy Clin Immunol 115: 418-419. [Crossref]

6. Prasad GA, Alexander JA, Schleck CD, Zinsmeister AR, Smyrk TC, et al. (2009) Epidemiology of eosinophilic esophagitis over three decades in Olmsted County, Minnesota. Clin Gastroenterol Hepatol 7: 1055-1061. [Crossref]

7. Mackenzie SH, Go M, Chadwick B, Thomas K, Fang J, et al. (2008) Eosinophilic oesophagitis in patients presenting with dysphagia-a prospective analysis. Aliment Pharmacol Ther 28: 1140-1146. [Crossref]

8. Veerappan GR, Perry JL, Duncan TJ, Baker TP, Maydonovitch C, et al. (2009) Prevalence of eosinophilic esophagitis in an adult population undergoing upper endoscopy: a prospective study. Clin Gastroenterol Hepatol 7: 420-426. [Crossref]

9. Spergel JM, Brown-Whitehorn TF, Cianferoni A, Shuker M, Wang ML, et al. (2012) Identification of causative foods in children with eosinophilic esophagitis treated with an elimination diet. J Allergy Clin Immunol 130: 461-467. [Crossref]

10. Collins MH, Blanchard C, Abonia JP, Kirby C, Akers R, et al. (2008) Clinical, pathologic, and molecular characterization of familial eosinophilic esophagitis compared with sporadic cases. Clin Gastroenterol Hepatol 6: 621-629. [Crossref]

11. Blanchard C, Wang N, Rothenberg ME (2006) Eosinophilic esophagitis: pathogenesis, genetics, and therapy. J Allergy Clin Immunol 118: 1054-1059. [Crossref]

12. Ober C (2005) Perspectives on the past decade of asthma genetics. J Allergy Clin Immunol 116: 274-278. [Crossref]

13. Straumann A, Schoepfer AM (2012) Therapeutic concepts in adult and paediatric eosinophilic oesophagitis. Nat Rev Gastroenterol Hepatol 9: 697-704. [Crossref]

14. Spergel JM (2007) Eosinophilic esophagitis in adults and children: evidence for a food allergy component in many patients. Curr Opin Allergy Clin Immunol 7: 274-278. [Crossref]
15. Kelly K, Lazenby A, Rowe P, Yardley JH, Perman JA, et al. (1995) Eosinophilic esophagitis attributed to gastroesophageal reflux: improvement with an amino acid based formula. Gastroenterology 109: 1503-1512. [Crossref]

16. Henderson CJ, Abonia JP, King EC, Putnam PE, Collins MH, et al. (2012) Comparative dietary therapy effectiveness in remission of pediatric eosinophilic esophagitis. $J$ Allergy Clin Immunol 129: 1570-1578. [Crossref]

17. Markowitz JE, Spergel JM, Ruchelli E, Liacouras CA (2003) Elemental diet is an effective treatment for eosinophilic esophagitis in children and adolescents. $\mathrm{Am} \mathrm{J}$ Gastroenterol 98: 777-782. [Crossref]

18. Peterson KA, Byrne KR, Vinson LA, Ying J, Boynton KK, et al. (2013) Elemental diet induces histologic response in adult eosinophilic esophagitis. Am J Gastroenterol 108: 759-766. [Crossref]

19. Cheung KM, Oliver MR, Cameron DJS, Catto-Smith AG, Chow CW (2003) Esophageal eosinophilia in children with dysphagia. J Pediatr Gastroenterol Nutr 37: 498-503. [Crossref]

20. Liacouras CA, Spergel JM, Ruchelli E, Verma R, Mascarenhas M, et al. (2005) Eosinophilic esophagitis: a 10-year experience in 381 children. Clin Gastroenterol Hepatol 3: 1198-1206. [Crossref]

21. Noel RJ, Putnam PE, Rothenberg ME (2004) Eosinophilic esophagitis. N Engl J Med 351: 940-941. [Crossref]

22. Sant'Anna AM, Rolland S, Fournet JC, Yazbeck S, Drouin E (2004) Eosinophilic esophagitis in children: symptoms, histology and $\mathrm{pH}$ probe results. J Pediatr Gastroenterol Nutr 39: 373-377. [Crossref]

23. Straumann A, Spichtin HP, Grize L, Bucher KA, Beglinger C, et al. (2003) Natural history of primary eosinophilic esophagitis. Gastroenterology 125: 1660-1669.

24. Dellon ES (2012) Diagnosis and management of eosinophilic esophagitis. Clin Gastroenterol Hepatol 10: 1066-1078. [Crossref]

25. Dellon ES (2013) Eosinophilic esophagitis. Gastroenterol Clin North Am 42: 133-153. [Crossref]

26. Papadopoulou A, Dias JA (2014) Eosinophilic esophagitis: an emerging disease in childhood-review of diagnostic and management strategies. Front Pediatr 2: 129 [Crossref]

27. Lamousé-Smith ES, Furuta GT (2006) Eosinophils in the gastrointestinal tract. Curr Gastroenterol Rep 8: 390-395. [Crossref]

28. Barlow WJ, Orlando RC (2005) The pathogenesis of heartburn in nonerosive reflux disease: a unifying hypothesis. Gastroenterology 128: 771-778. [Crossref]

Copyright: (C2018 Qualia C. This is an open-access article distributed under the terms of the Creative Commons Attribution License, which permits unrestricted use, distribution, and reproduction in any medium, provided the original author and source are credited. 